\title{
Age-related Differences in the Expression of Proto-oncogene and Contractile Protein Genes in Response to Pressure Overload in the Rat Myocardium
}

\author{
Toshiyuki Takahashi, ${ }^{\star \ddagger}$ Heribert Schunkert, ${ }^{\ddagger}$ Shogen Isoyama, ${ }^{\ddagger}$ Jeanne Y. Wei, ${ }^{\ddagger \$}$ \\ Bernardo Nadal-Ginard," William Grossman, ${ }^{\ddagger}$ and Seigo Izumo** \\ ${ }^{*}$ Molecular Medicine Unit and Department of Medicine ( ${ }^{\ddagger}$ Cardiovascular and ${ }^{\S}$ Gerontology Divisions), Beth Israel Hospital, \\ "Department of Cardiology, Children's Hospital, and Departments of Medicine and Pediatrics, Harvard Medical School, Boston, \\ Massachusetts 02215
}

\begin{abstract}
Cardiac adaptation to hemodynamic stress involves both quantitative (hypertrophy) and qualitative (pattern of gene expression) changes. Our previous studies have shown that advancing age in the rat is associated with diminished capacity to develop left ventricular hypertrophy in response to either ascending aortic constriction (AoC). In this study, we examined whether the expression of protooncogenes and contractile protein genes in response to $\mathrm{AoC}$ differs between adult (9-mo-old) and old (18-mo-old) rats. RNA was isolated from the left ventricles of AoC animals of both age groups subjected to a similar hemodynamic stress. Immediately after $\mathrm{AoC}$, the levels of the ventricular expression of c-fos and c-jun protooncogenes were markedly lower in the old rats than in the adult animals. $5 \mathrm{~d}$ after the operation, the ratio of $\beta$ - to $\alpha$-myosin heavy chain mRNAs increased significantly after $\mathrm{AoC}$ in both age groups. In contrast, $\mathrm{AoC}$ was associated with a marked reduction in the levels of $\mathrm{mRNAs}$ encoding sarcoplasmic reticulum $\mathrm{Ca}^{2+}$-ATPase (by $69 \%$ ) and cardiac calsequestrin (by $49 \%$ ) in the old rats but not in the adults. The mRNAs encoding atrial natriuretic factor and skeletal $\alpha$-actin increased in response to AoC only in the adult rats. There were no significant differences in expression of the cardiac $\alpha$-actin mRNA among the experimental groups. These data suggest that $(a)$ the expression of protooncogenes in response to acute pressure overload is significantly reduced in the aged rats and $(b)$ the pattern of expression of the contractile protein gene in response to $\mathrm{AoC}$ in the old rats differs qualitatively as well as quantitatively from that in younger animals. These age-related differences may play a role in the higher frequency of heart failure in the aged during hemodynamic stress. (J. Clin. Invest. 1992. 89:939-946.) Key words: actin • myosin heavy chain $•$ calsequestrin $\cdot \mathrm{Ca}^{2+}$-ATPase $\bullet$ atrial natriuretic factor
\end{abstract}

Part of this work was presented at the 62nd Annual Scientific Sessions of the American Heart Association on 15 November 1989, in New Orleans, LA. Portions of this work have been published in abstract form (1989. Circulation. 80 (Suppl. II):II-457).

Address correspondence to S. Izumo, M.D., Molecular Medicine Unit, Beth Israel Hospital, 330 Brookline Avenue, Boston, MA 02215.

Received for publication 22 February 1991 and in revised form 28 October 1991.

J. Clin. Invest.

(C) The American Society for Clinical Investigation, Inc.

0021-9738/92/03/0939/08 \$2.00

Volume 89, March 1992, 939-946

\section{Introduction}

The phenomenon of senescence is of fundamental importance for the function of cardiac muscle because, like neurons, cardiac myocytes are terminally differentiated cells and their life span is as long as that of the whole organism. Since adult cardiac cells are unable to divide, the ability of the heart to adapt to increased hemodynamic load, either from hypertension, valvular heart disease, or loss of myocardium due to ischemic heart disease, is critically dependent on its capacity to develop hypertrophy (1-3). When functional demands exceed adaptive limits, heart failure ensues $(3,4)$.

It is well known that, when subjected to similar hemodynamic stress, old patients develop heart failure more frequently than their younger cohorts $(5,6)$. This higher incidence of heart failure in old patients might be due to a diminished capacity for cardiac hypertrophy in response to a given stress. It has been shown that the extent of cardiac hypertrophy induced by exercise is substantially less in the senescent than in young adult animals (7). Our previous studies have confirmed that the capacity for left ventricular (LV) ${ }^{1}$ hypertrophy in response to pressure or volume overload diminishes with advancing age $(8,9)$.

Cardiac adaptations to hemodynamic stress also involve altered pattern of gene expression. Changes in expression of a variety of cardiac genes in response to overload have been summarized as the acute induction of protooncogenes, followed by the reinduction of fetal isoforms of contractile proteins (10-12) such as $\beta$-myosin heavy chain (MHC) $(13,14)$ and skeletal $\alpha$-actin $(10,15)$. In addition, pressure overload has been shown to markedly increase ventricular mRNA levels of atrial natriuretic factor (ANF) $(10,16,17)$ and to significantly decrease the mRNA levels of sarcoplasmic reticulum (SR) $\mathrm{Ca}^{2+}$-ATPase (18-20). Thus, hemodynamic stress changes the levels of these mRNA species similar to those observed during the fetal stage $(10,11,18)$.

Normal myocardial aging also involves both quantitative and qualitative alterations $(21,22)$. Morphologically, interstitial fibrosis and myocyte hypertrophy have been observed in the left ventricles of normal aged rats $(22,23)$. Physiological studies of LV papillary muscle preparations have revealed that the duration of tension and the time to half-relaxation were prolonged in aged rats compared with in their younger cohort $(21,24)$. The prolongation of myocardial contraction has been

1. Abbreviations used in this paper: $\mathrm{AoC}$, ascending aortic constriction; ANF, atrial natriuretic factor; GAPDH, glyceraldehyde-3-phosphate dehydrogenase; MHC, myosin heavy chain; SR, sarcoplasmic reticulum. 
attributed to a decline of $\mathrm{Ca}^{2+}$-activated myosin-ATPase activity, secondary to a decrease in the percentage of $\alpha-\mathrm{MHC}_{\text {or }} \mathrm{V}_{1}$ isozyme $(25,26)$. The abnormal myocardial relaxation has been thought to reflect age-related decreases in $\mathrm{Ca}^{2+}$-uptake by the $\operatorname{SR}(27,28)$.

In the present study, we asked the following questions. First, can the aging process affect changes in cardiac gene expression in response to aortic constriction (AoC)? Second, do qualitative changes in the pattern of gene expression occur in response to an ascending $\mathrm{AoC}$ in the old animals, in spite of the absence of quantitative hypertrophic responses (8)? These two questions may be important because they may be related both to fundamental mechanisms concerning the effects of aging on regulation of gene expression and to clinical problems concerning the age-related differences in the frequency of heart failure. To answer these questions, we examined expression of genes encoding two protooncogenes (c-fos and c-jun), two SR proteins (SR $\mathrm{Ca}^{2+}$-ATPase and cardiac calsequestrin), two isoforms of sarcomeric proteins (skeletal and cardiac $\alpha$-actins and $\alpha$ - and $\beta$-MHC) and a secreted protein (ANF) in the LV myocardium of the adult (9-mo-old) and old (18-mo-old) rats with or without pressure overload.

\section{Methods}

\section{Materials}

Two age groups (9 and 18 mo old) of male Fisher 344 rats (Harlan Sprague Dawley, Inc., Indianapolis, IN) were obtained under contract with the National Institute of Aging. Average life span of the males of this colony is $\sim 24 \mathrm{mo}$. The rats of this species do not gain body weight between 9 and 18 mo of age, and their blood pressure does not change during this time period (8).

\section{Operative procedures}

Operative procedures for producing an ascending AoC were described in detail previously (8). Briefly, each rat was anesthetized either with brevital $(50 \mathrm{mg} / \mathrm{kg}$ i.p.) or with methohexital sodium $(60 \mathrm{mg} / \mathrm{kg}$ i.p.). The rats were intubated and respiration was controlled by a rodent ventilator (model 683; Harvard Apparatus, South Natick, MA) with room air. The left thorax was opened at the third intercostal space to expose the ascending aorta. The ascending aorta was carefully dissected free from the pulmonary artery and surrounding tissues, and a surgical thread (1-0 silk) was drawn under the ascending aorta. A 16-gauge needle $(1.6 \mathrm{~mm}$ o.d.) was placed alongside the ascending aorta, and the aorta and needle were tied tightly together with the thread. The needle was then removed, leaving the ascending aorta constricted to a diameter of $1.6 \mathrm{~mm}$. The thorax was closed with a silk suture, whereas the lungs were inflated with positive end-expiratory pressure. For shamoperated groups, the identical procedure was performed, except that induction of AoC was not done. As reported previously (8), operative mortalities of 9- and 18-mo-old rats with $\mathrm{AoC}$ were 15 and 23\%, respectively.

\section{$R N A$ measurement and analyses}

RNA analyses were performed in groups of 56 animals $(n=28$ each for 9- and 18-mo-old rats) that had undergone the operations described above, creating AoC $(n=34)$ or performing a sham operation $(n=22)$. Rats were killed at 30, 45, 60, 90, and $180 \mathrm{~min}$ after $A \circ C$ for the study of protooncogenes and at $5 \mathrm{~d}$ for the study of contractile protein gene expression. The left ventricle was carefully dissected from the atria and right ventricle and stored in liquid nitrogen until use. Total cellular RNA was extracted by the guanidinium-hot phenol method. The RNA concentration in the LV myocardium was determined by spectrophotometry, with the absorbance at $260 \mathrm{~nm}$. The ratio of the absorbance at $280 \mathrm{~nm}$ was $>1.9$ in all the samples.
RNA blot analysis. 20- $\mu \mathrm{g}$ samples of total cellular RNA from each animal were size fractionated by electrophoresis on a $1.0 \%$ agarose-formaldehyde gel and transferred to nylon or nitrocellulose filters. The filters were prehybridized in the solution mix (containing $50 \%$ formamide, $5 \times$ standard saline citrate [SSC; $1 \times=0.15 \mathrm{M} \mathrm{NaCl}, 0.015 \mathrm{M}$ sodium citrate], $5 \times$ Denhardt's solution, $0.2 \%$ SDS, $0.025 \mathrm{M}$ sodium phosphate, and $250 \mu \mathrm{g} / \mathrm{ml}$ calf thymus DNA) at $42^{\circ} \mathrm{C}$ for $\geq 2 \mathrm{~h}$ and hybridized with specific DNA probes in the same solution mix plus $10 \%$ dextran sulfate, at $42^{\circ} \mathrm{C}$, for $16 \mathrm{~h}$. For the 18-S rRNA oligonucleotide probe, double-distilled water was substituted for formamide. At the end of hybridization, the filters were washed serially, with the final wash in $0.1 \times$ SSC $-0.2 \%$ SDS at $65^{\circ} \mathrm{C}$ for $15-90 \mathrm{~min}$, except for the skeletal $\alpha$-actin probe (in $0.5 \times \mathrm{SSC}-0.1 \% \mathrm{SDS}$ at $55^{\circ} \mathrm{C}$ for $15 \mathrm{~min}$ ) and the 18-S rRNA probe (in $3 \times \mathrm{SSC}$ at room temperature for $30 \mathrm{~min}$ ). DNA probes used in this study were as follows: (a) c-fos: a 2.1-kb EcoRI fragment of the mouse c-fos cDNA clone pGEM-fos (a generous gift from Dr. M. E. Greenberg); (b) c-jun: a 2.1-kb fragment of the mouse c-jun cDNA (29); (c) SR Ca ${ }^{2+}$-ATPase: a 0.7-kb PstI fragment generated from the carboxy terminal and $3^{\prime}$ untranslated region of the cDNA clone pCA, specific for the rabbit cardiac-slow twitch skeletal muscle SR Ca ${ }^{2+}$-ATPase (30); (d) cardiac calsequestrin: a 1.9-kb EcoRI fragment from a cDNA clone IC $3 \mathrm{~A}$, containing the entire coding region and $3^{\prime}$ untranslated region of a canine cardiac calsequestrin (31); (e) ANF: a synthetic 84-nucleotide-long oligonucleotide complementary to the entire coding sequence of the rat $\operatorname{ANF}(32) ;(f)$ skeletal $\alpha$-actin: a synthetic oligonucleotide complementary to the first 57 nucleotides of the $3^{\prime}$ untranslated region of the mouse skeletal $\alpha$-actin cDNA (33); $(g)$ cardiac $\alpha$-actin: a synthetic oligonucleotide complementary to the first 55 nucleotides of the $5^{\prime}$ untranslated region of the mouse actin cDNA (33); (h) glyceraldehyde-3-phosphate dehydrogenase (GAPDH): a 1.3$\mathrm{kb}$ PstI fragment from cDNA pUC-GAPDH13, containing the entire coding region and a part of 3 ' untranslated region of the rat GAPDH (34); and $(i)$ 18-S rRNA: a synthetic oligonucleotide (5'-ACGGTATCTGATCGTCTTCGA-3') complementary to the rat 18-S rRNA (35). The cDNA probes were labeled by random priming method with $\left.{ }^{32} \mathrm{P}\right] \mathrm{dCTP}(3,000 \mathrm{Ci} / \mathrm{mmol}$, New England Nuclear, Boston, MA) and the synthetic oligonucleotide probes with $\mathrm{T}_{4}$ polynucleotide kinase and $\left.{ }^{32} \mathrm{P}\right] \gamma \operatorname{ATP}(3,000 \mathrm{Ci} / \mathrm{mmol}$, New England Nuclear) (36).

The blots were exposed on $x$-ray films with intensifying screens for $1-7 \mathrm{~d}$ at $-80^{\circ} \mathrm{C}$. Relative amounts of each mRNA were determined by laser densitometry in the linear response range of the $x$-ray films. The densitometric scores of specific mRNAs were "normalized" by that of GAPDH mRNA, which encodes a constitutively expressed glycolytic enzyme, as an internal control. Normalization by 18-S ribosomal RNA signals or by the cardiac $\alpha$-actin signals produced similar results. The mean value of the normalized scores of mRNA from sham-operated, adult (9-mo-old) animals was arbitrarily determined as 1.0 for each mRNA species.

S1 nuclease mapping. S1 mapping analysis was performed as previously described (14). Briefly, $20 \mu \mathrm{g}$ of total RNA was hybridized in $80 \%$ formamide at $42^{\circ} \mathrm{C}$ for $16 \mathrm{~h}$ with a $3^{\prime}$ end-labeled, single-stranded probe, generated from the $3^{\prime}$ end PstI fragment of NB3, a cDNA specific for the rat $\beta$-MHC (14). This 347-nucleotide-long probe contains 180 nucleotides of common coding sequence at the carboxy terminal of the $\alpha$ - and $\beta$-MHC, in addition to the entire $3^{\prime}$ untranslated sequence of the $\beta$-MHC gene, which diverges completely from the $\alpha$-MHC gene. This probe also contains 43 nucleotides of oligo (dT) tails. S1 nuclease digestion was done with $150 \mathrm{U}$ of enzyme (New England Nuclear) and the digestion products were size-separated on $7 \%$ polyacrylamide- 8.3 $M$ urea-sequencing gel. The gel was dried and exposed on an x-ray film at $-80^{\circ} \mathrm{C}$ as mentioned above. The relative amounts of $\alpha$ - and $\beta$-MHC mRNAs were quantitated by laser densitometry in the linear range of the $x$-ray film.

\section{Statistical analyses}

All data are expressed as means \pm SEM. The statistical significance of differences in mean values between two groups was assessed by the 
unpaired Student's $t$-test with Bonferroni's correction or Fisher's exact test if overall significance was demonstrated by analysis of variance (37). Significance was accepted at $P<0.05$ level.

\section{Results}

The present study is a direct extension of our previous study concerning the hemodynamic and morphological changes in response to $\mathrm{AoC}$ in the rat $\mathrm{LV}$ myocardium (8). Table I summarizes the results of the hemodynamic and morphological parameters in this model. The degrees of the severity of pressure overload imposed on the left ventricles were similar in both age groups (LV peak systolic pressure in $\mathrm{mmHg}$ : sham $91 \pm 3$ and AoC $127 \pm 13$ for the adult; sham $95 \pm 9$ and AoC $124 \pm 14$ for the old). This pressure overload caused a moderate but significant LV hypertrophic response (23\% increase in LV dry weight in $4 \mathrm{wk}$ ) in the adult rats but no responses in the old rats. At histological level, the mean value of myocyte width in the sham-operated old animals was much larger than that in the sham-operated adults $(29.2 \pm 1.4$ vs. $20.4 \pm 0.8 \mu)$. AoC increased the mean value of myocyte width significantly (from $20.4 \pm 0.8$ to $25.9 \pm 0.9 \mu \mathrm{m}$ ) in the adult rats but did not cause a further increase in this index in the old. These age-related differences in LV hypertrophic responses to AoC were also evident in the LV myocardial RNA concentration, which also increased significantly ( $21 \%$ over sham) in the adult, but by only $4 \%$ in the old. Thus, at the moderate pressure overload used in this model, LV hypertrophy occurred in the adult but not in the old rats.

In this study, we asked whether the aging process affects changes in cardiac gene expression in response to $\mathrm{AoC}$, in spite of the absence of quantitative hypertrophic response in the old animals. First, we examined expression of two "immediate early" genes, c-fos and c-jun protooncogenes, in response to acute pressure overload. As shown in Fig. 1, c-fos, mRNA was markedly induced at $90 \mathrm{~min}$ after AoC in 9-mo-old rats, but its expression was significantly reduced in 18-mo-old animals. The induction of c-fos was transient, inasmuch as its level of expression returned to near the baseline by $180 \mathrm{~min}$ after AoC. This age-related difference in c-fos expression was also observed when the animals were killed at earlier time points (30, 45, and $60 \mathrm{~min}$ ) after AoC (data not shown). Expression of c-jun in response to AoC was also reduced in the old rats compared with the adults at $90 \mathrm{~min}$ after $\mathrm{AoC}$. Thus, the old hearts appear to have an attenuated nuclear response to acute pressure overload, as determined by the two-protooncogene induction.

Next, we examined expression of various contractile protein genes in response to AoC. One of the well-studied biochemical markers of hypertrophy in the rat is increased $\beta-\mathrm{MHC} / \alpha-$ MHC ratio. To determine the levels of $\alpha$ - and $\beta$-MHC mRNAs, we performed $\mathrm{S} 1$ nuclease mapping analysis (Fig. 2). S1 digestion produced two protected bands of 180 and 304 nucleotides, corresponding to $\alpha$ - and $\beta$-MHC mRNAs, respectively. In 9mo-old animals, the level of $\beta$-MHC mRNA was significantly higher than in young (2-3-mo-old) animals (14). The ratio of $\beta / \alpha$ MHC mRNAs was similar between the 9- and 18-mo-old sham-operated rats. In response to $\mathrm{AoC}$, the $\beta / \alpha$ ratio increased to a similar degree in both age groups. In the adult rats, this increase in the $\beta / \alpha$ ratio seemed to be achieved primarily by an increase in the $\beta$-MHC mRNAs, whereas in the old rats the same increase appeared to be achieved primarily by a decrease in the $\alpha$-MHC mRNA. Thus, in response to pressure overload, the $\beta / \alpha$ ratio increased in both age groups, but possibly by different mechanisms.

We also examined changes in the level of the SR $\mathrm{Ca}^{2+}$-ATPase mRNA in response to AoC. Northern blot analysis has detected an mRNA species of $\sim 4 \mathrm{~kb}$ in the rat $\mathrm{LV}$ myocardium (Fig. 3, top row). Densitometric analysis of the hybridizing signal from each animal revealed that the level of the SR $\mathrm{Ca}^{2+}$-ATPase mRNA, corrected by GAPDH signals, remained unchanged after $\mathrm{AoC}$ in the adult rats but decreased markedly (by $69 \%, P<0.01$ ) in the old rats (Fig. 4, left). Slot blot analysis of RNA yielded a very similar result (data not shown). Similar results were also obtained when the SR $\mathrm{Ca}^{2+}$-ATPase signals were corrected either by the $\alpha$-cardiac actin signals or by the 18-S ribosomal signals (data not shown).

The aging process alone, at least until age $18 \mathrm{mo}$, did not alter expression of the SR $\mathrm{Ca}^{2+}$-ATPase gene, because there was no significant difference in the level of this mRNA species between the sham-operated adult and old rats. However, at very advanced age $(30 \mathrm{mo})$, the SR $\mathrm{Ca}^{2+}$-ATPase mRNA was reported to be decreased by $60 \%$ compared with young (4-moold) animals (38).

We then analyzed expression of cardiac calsequestrin, a high capacity and medium affinity $\mathrm{Ca}^{2+}$-binding protein localized at the terminal cisternae portion of cardiac SR (31). Little is known concerning regulation of the cardiac calsequestrin

Table I. Changes in Hemodynamic and Morphological Parameters and RNA Concentration in the LV Myocardium in Response to AoC in the Adult (9-mo-old) and old (18-mo-old) Rats

\begin{tabular}{|c|c|c|c|c|}
\hline & \multicolumn{2}{|c|}{ Adult } & \multicolumn{2}{|c|}{ Old } \\
\hline & Sham & $\mathrm{AoC}$ & Sham & $\mathrm{AoC}$ \\
\hline LVPSP (mmHg) & $91 \pm 3$ & $127 \pm 13^{*}$ & $95 \pm 9$ & $124 \pm 14^{\ddagger}$ \\
\hline LVEDP (mmHg) & $4.6 \pm 0.8$ & $5.6 \pm 0.9$ & $5.1 \pm 1.0$ & $6.0 \pm 0.6$ \\
\hline LV dry weight/body weight (mg/g) & $0.47 \pm 0.01$ & $0.58 \pm 0.03^{\ddagger}$ & $0.49 \pm 0.01$ & $0.49 \pm 0.01$ \\
\hline LV dry weight/tibial length $(\mathrm{mg} / \mathrm{cm})$ & $39 \pm 1$ & $44 \pm 2^{\ddagger}$ & $39 \pm 1$ & $39 \pm 2$ \\
\hline Myocyte width $(\mu \mathrm{m})$ & $20.4 \pm 0.8$ & $25.9 \pm 0.9^{\ddagger}$ & $29.2 \pm 0.6$ & $29.2 \pm 1.4$ \\
\hline RNA Concentration $(\mu \mathrm{g} / \mathrm{g}$ wet $w \mathrm{t})$ & $963 \pm 22$ & $1,168 \pm 31^{\ddagger}$ & $980 \pm 10$ & $1,021 \pm 16$ \\
\hline
\end{tabular}

Data are means \pm SE. ${ }^{*} P<0.05,{ }^{\ddagger} P<0.01$ compared with sham of the same age group. See reference 8 for more detailed hemodynamic and morphological data. LV, left ventricular; PSP and EDP, peak systolic and end-diastolic pressures, respectively. Adults were 9 mo and old rats were 18 mo old. 

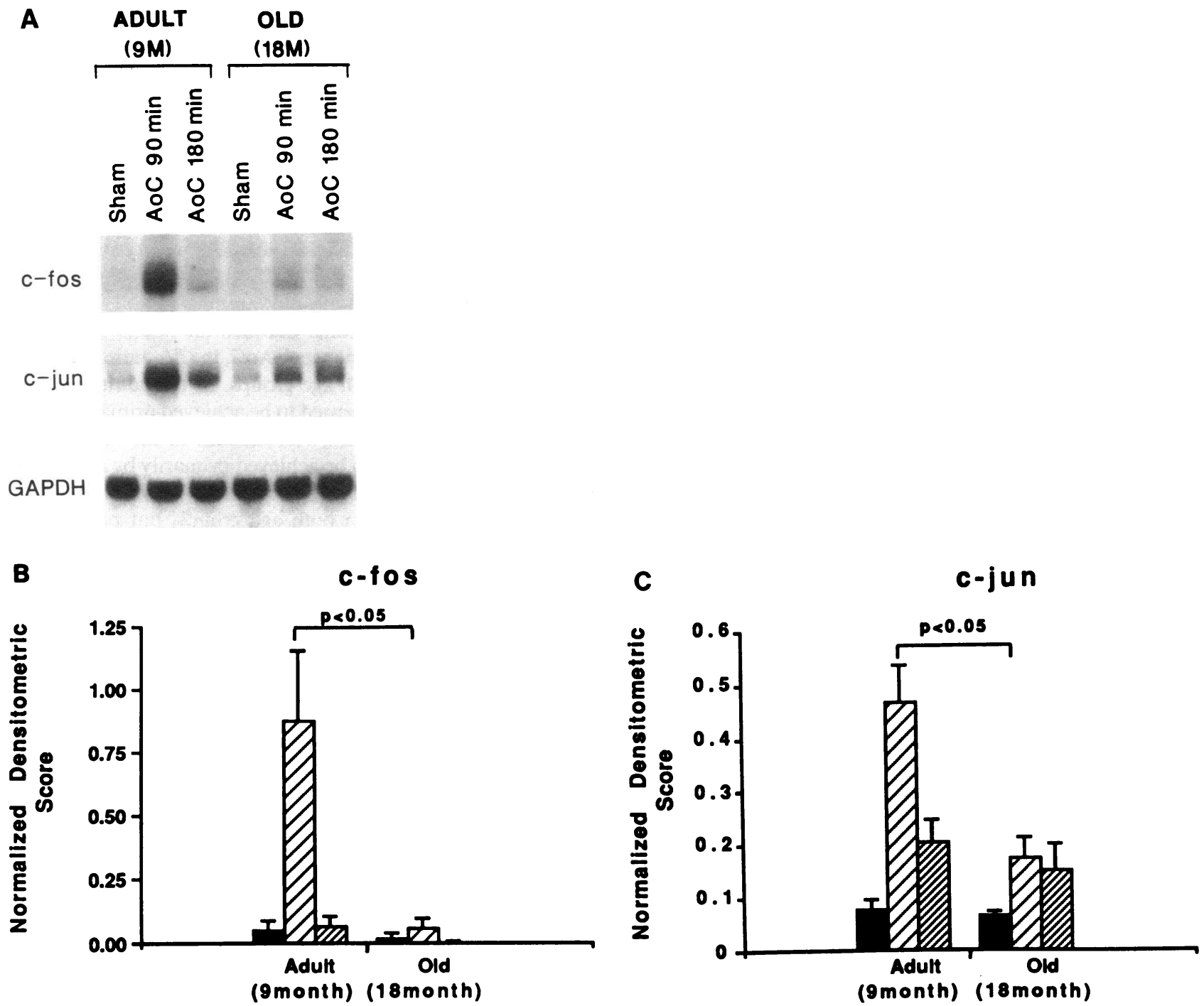

Figure 1. Expression of c-fos and c-jun mRNA in response to acute pressure overload. $(A)$ RNA blot hybridization. The same blot was hybridized with c-fos, c-jun, and GAPDH cDNA probes. $(B$ and $C$ ) Normalized densitometric scores. The signals of c-fos and c-jun were corrected by those of GAPDH. The numbers of samples are $n=3$ for sham in each group; $n=6$ for sham in each group; $n=6$ for AoC in each group. $n$, Sham; $\square$, AoC $90 \mathrm{~min}$; $\mathrm{AOC} 180 \mathrm{~min}$.

gene, particularly in pathologic states such as cardiac hypertrophy and failure. Northern blot analysis (Fig. 3, 2nd row) indicated that a single cardiac calsequestrin mRNA species of $2.9 \mathrm{~kb}$ was expressed in the rat $\mathrm{LV}$ myocardium. The level of cardiac calsequestrin mRNA expression did not change in response to AoC in the adult rats but decreased significantly (by $49 \%, P<0.05$ ) in the aged rats (Fig. 4 , right). There was no age-related difference in expression of this SR protein gene in the sham-operated animals.

Fig. 5 shows the representative RNA blot analyses of mRNAs encoding ANF and skeletal and cardiac $\alpha$-actins in the sham-operated and $\mathrm{AoC}$ rats of both age groups, and Fig. 6 summarizes changes in the relative abundance of mRNAs by densitometric analysis. By RNA blot analysis (Fig. 5, top row), LV expression of ANF mRNA ( 1.0 kb) was barely detectable. However, the mean level of ANF mRNA increased in response to $\mathrm{AoC}$ in the adult rats. The level of ANF mRNA was already high in the sham-operated old rats. AoC failed to cause a further significant increase in the level of this mRNA in the old rats (Fig. $6 \mathrm{~A}$ ).

The mean level of skeletal $\alpha$-actin mRNA increased in response to $\mathrm{AoC}$ in the adult rats (Fig. 5, 2nd row, and Fig. $6 B$ ). In the old sham-operated rats, the level of skeletal $\alpha$-actin mRNA was not different from that in the adult sham-operated rats and AoC did not increase expression of this mRNA species. The level of cardiac $\alpha$-actin mRNA was not different among the experimental groups. (Fig. 5, 3rd row, and Fig. $6 C$ ).

\section{Discussion}

This study demonstrated that the pattern of expression of cardiac gene expression in response to pressure overload differs markedly between the adult and aged animals. Expression of two immediate early genes, c-fos and c-jun, in response to AoC is markedly attenuated in the old rats. In contrast, expression of some cardiac genes ( $\mathrm{SR} \mathrm{Ca}^{2+}$-ATPase, cardiac calsequestrin, 


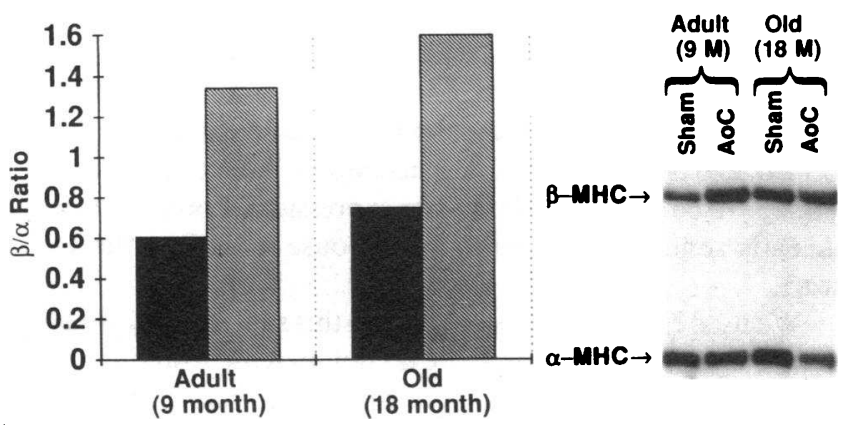

Figure 2. Expression of the $\alpha$ - and $\beta$-MHC mRNAs in the LV myocardium. S1 nuclease mapping analysis was performed with a $3^{\prime}$ endlabeled, single-strand probe, generated from the $3^{\prime}$ end PstI fragment of NB3, cDNA-specific for the rat $\beta$-MHC $(3,10)$. Each lane represents the pooled sample from five animals of each group. S1 digestion created two protected bands of 180 and 304 nucleotides, corresponding to $\alpha$ - and $\beta$-MHC mRNAs, respectively. Relative amounts of the $\alpha$ - and $\beta$-MHC mRNAs were determined by laser densitometry and the ratio of $\beta$-MHC to $\alpha-\mathrm{MHC}(\beta / \alpha)$ was calculated and shown in the bar graph. The $\beta / \alpha$ ratio increased similarly in both age groups in response to AoC. $a$, Sham; a, AoC.

and $\mathrm{MHCs}$ ) changed in response to $\mathrm{AoC}$ in the old rats, in spite of the absence of $\mathrm{LV}$ hypertrophic response in this group of animals. On the other hand, the levels of mRNAs encoding ANF and skeletal $\alpha$-actin did not change after AoC in the old animals. These data suggest that there exists a dissociation be-

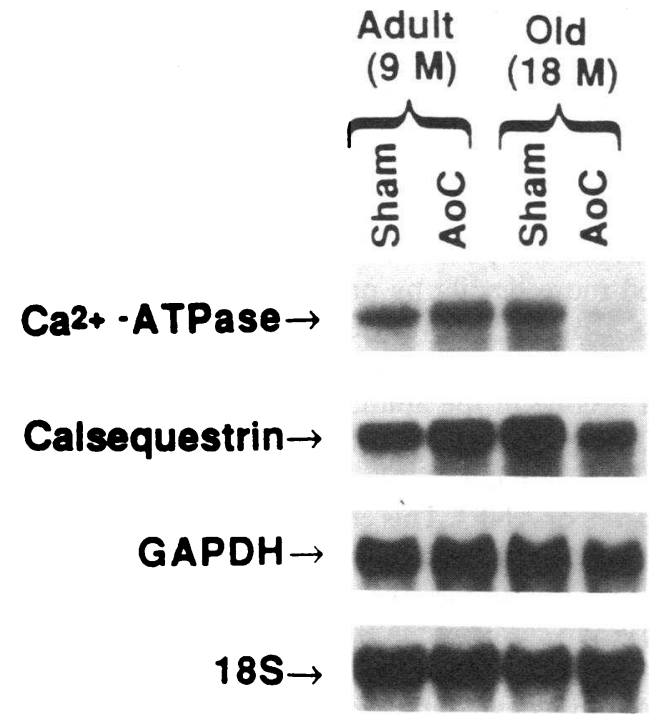

Figure 3. Expression of mRNAs encoding the $\mathrm{SR} \mathrm{Ca}^{2+}$-ATPase and cardiac calsequestrin in the rat LV myocardium. RNA blot hybridization was carried out with cDNA clones specific for the rabbit cardiac-slow twitch skeletal SR $\mathrm{Ca}^{2+}$-ATPase (27) and canine cardiac calsequestrin (25). The SR $\mathrm{Ca}^{2+}$-ATPase cDNA probe (pCA) hybridized with an mRNA species of $\sim 4 \mathrm{~kb}$. The cardiac calsequestrin cDNA probe (IC3A) produced a single band of $\sim 2.9 \mathrm{~kb}$. In contrast to the canine heart (25), the additional band of $2.2 \mathrm{~kb}$ was not detected with the ICA3 clone in the rat LV myocardium. The same blot was hybridized with a cDNA for GAPDH (29) and a synthetic oligonucleotide for 18-S rRNA as internal controls. Each lane represents the pooled sample from five animals of each group. Expression of the SR $\mathrm{Ca}^{2+}$-ATPase and calsequestrin mRNAs decreased markedly in the old $\mathrm{AOC}$ animals but remained unchanged in the adult animals.
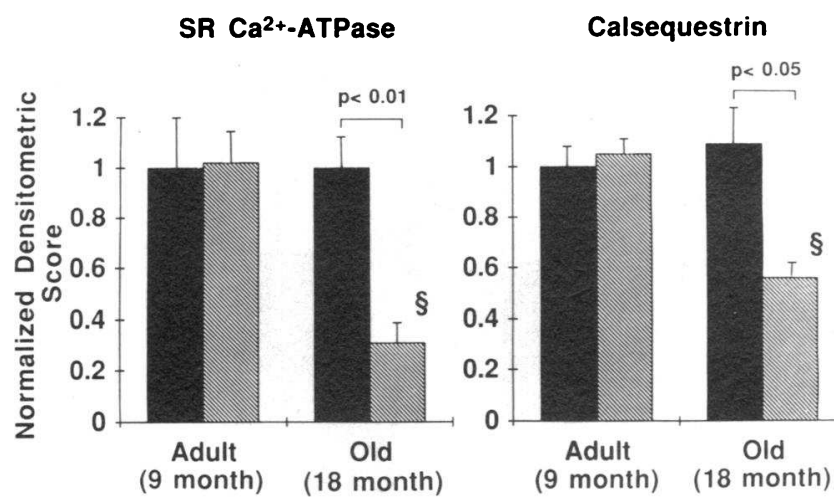

Figure 4. Changes in the levels of mRNAs encoding the SR $\mathrm{Ca}^{2+}$-ATPase (left) and cardiac calsequestrin (right) in response to $\mathrm{AoC}$. The relative abundance of the SR $\mathrm{Ca}^{2+}$-ATPase mRNA (normalized by the level of GAPDH mRNA) remained unchanged in response to $A O C$ in the adult rats, but decreased markedly (by $69 \%$, $P<0.01)$ in the old rats. The level of cardiac calsequestrin mRNA also decreased significantly (by $49 \%, P<0.05$ ) after $\mathrm{AOC}$ in the old rats but not in the adult. $n=5$ for each group. ${ }^{8} P<0.01$ adult vs. old animals. $₫$, Sham; \pm , AoC.

tween the quantitative (hypertrophy) and qualitative (patterns of gene expression) responses of the LV myocardium to the hemodynamic stress and aging on cardiac gene expression were complex and varied with individual genes studied, suggesting that underlying molecular mechanisms for the altered expression of these genes may also be complex.

Recent studies have shown that senescent human cultured fibroblasts failed to proliferate in response to serum (39) or platelet-derived growth factor (40). Interestingly, expression of c-fos gene failed to increase by serum stimulus in the senescent cells (39). These findings are reminiscent of our results because the old myocardium had very diminished expression of c-fos and c-jun and failed to develop hypertrophy in response to

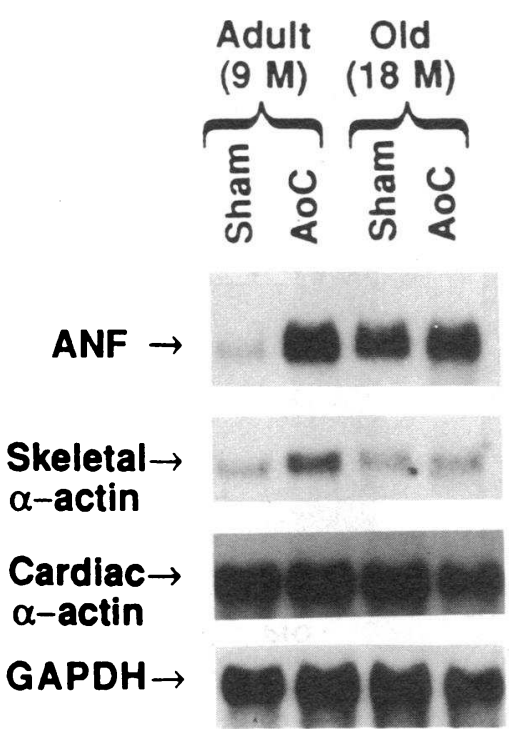

Figure 5. Representative RNA blot analysis of the expression of mRNAs encoding ANF and skeletal and cardiac $\alpha$-actins in the rat LV myocardium. Each lane represents the pooled samples of five animals of each group. Synthetic oligonucleotides were used for the hybridization. The mean level of ANF mRNA ( $1.0 \mathrm{~kb}$ in size) more than doubled in response to $\mathrm{AoC}$ in the adult rats. In contrast, ANF mRNA was already high in the LV myocardium from the old sham-operated rats and did not increase

further after AoC. The mean level of skeletal $\alpha$-actin mRNA (1.8 kb) also elevated by twofold in the adult rats with $A O C$ but showed no changes in the old animals. The level of cardiac $\alpha$-actin mRNA (1.8 kb) was not different among the experimental groups. 
A

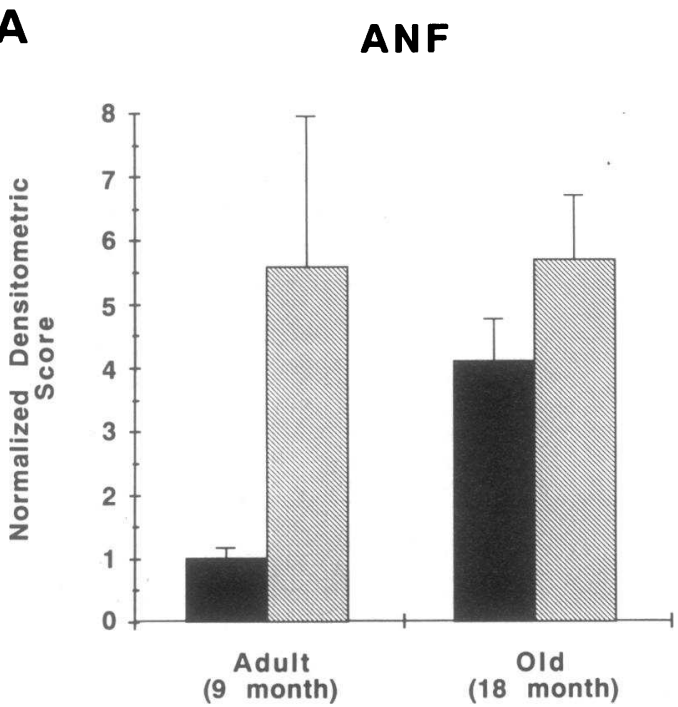

B

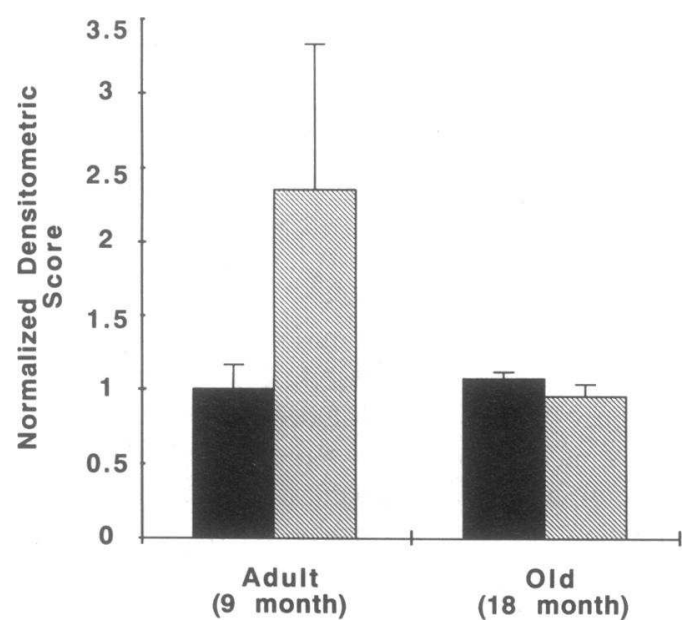

C

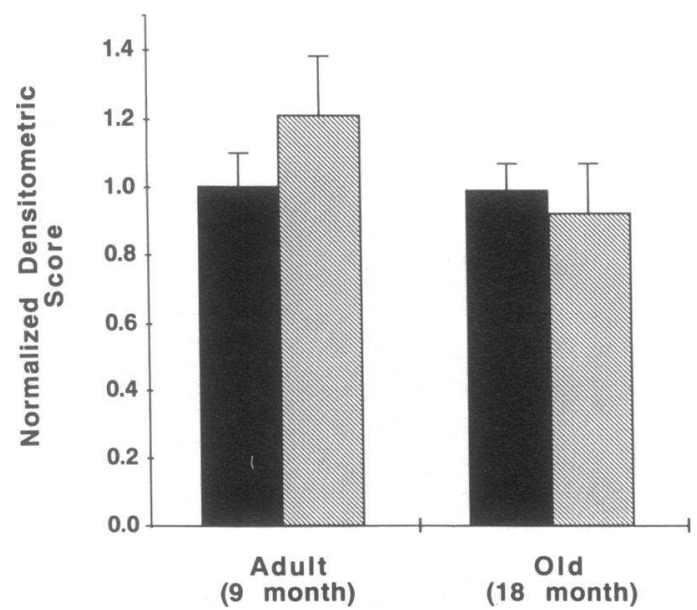

Figure 6. Densitometric analysis of the levels of mRNAs encoding ANF $(A)$ and skeletal $(B)$ and cardiac $\alpha$-actin $(C)$ in the LV myocardium. The relative abundance of the specific mRNA species was normalized by the level of GAPDH mRNA in each animal. $n=5$ for each group. $n$, Sham; $₫$, AoC.
AoC. Such similarity may imply that common mechanisms might underlie the aging process of the cell growth system in cardiocytes and other cell types. It should be noted, however, that at present there is no formal proof that expression of protooncogene is causatively linked to cardiac hypertrophy. It also remains to be determined whether expression of other immediate early genes is also reduced in response to $\mathrm{AoC}$ in the aged heart.

We used Fisher 344 rats because in this species body weight, heart weight, and blood pressure do not increase from the adult stage to old age. In contrast, Sprague-Dawley and Long-Evans rats develop age-related cardiac enlargement. Fisher 344 rats are also known to have significant age-related myocyte loss (22). Consistent with this finding, our histological study showed that the mean value of myocyte width in the shamoperated old animals was significantly larger than that in the adult sham-operated rats $(29.2 \pm 0.6$ vs. $20.4 \pm 0.8 \mu \mathrm{m})$. Thus, advancing age alone appears to cause hypertrophy at the cellular, but not at the organ, level to compensate for myocyte loss accompanying the aging process.

AoC increased the mean value of myocyte width from 20 to $26 \mu \mathrm{m}$ in the adult rats but did not cause a further increase in this index in the old. On the other hand, the biochemical phenotype of the stressed myocardium of the old animals is very similar to that of the advanced hypertrophy in the young (1020). This indicates that the senescent myocytes are able to sense increased load and change the pattern of gene expression. However, they are unable to increase their size further, at least not in response to the moderate pressure overload used in this study. It is possible that the senescent myocytes may be approaching the limit in size during the normal aging process. In this regard, it is noteworthy that hypertrophied ventricles of young rats (produced by $\mathrm{AoC}$ ) had very diminished expression of c-fos and c-jun in response to acute pressure overload in vitro compared with those in nonhypertrophied ventricles (41).

An alternative interpretation of the age-related differences might be considered. It is possible that proliferation of fibroblasts is triggered more readily by pressure overload in aged than in adult rats. Dilution of myocyte RNA with nonmyocyte RNA in the total RNA preparation could create the spurious appearance of a decline in the abundance of certain mRNA species $\left(\mathrm{Ca}^{2+}\right.$-ATPase or calsequestrin) and mask overload-induced increases in abundance of other species ( $\beta$-MHC, skeletal actin, c-fos, c-jun, or ANF). This effect may not be detected by the GAPDH or 18-S RNA control signals. However, it is highly unlikely that this is the sole cause of the age-related differences observed in cardiac gene expression, because $(a)$ the decrease in the $\mathrm{Ca}^{2+}$-ATPase and calsequestrin mRNAs in the aged rats with $\mathrm{AoC}$ was evident even when corrected by the level of the cardiac actin mRNA, a myocyte-specific gene product; $(b)$ the age-related differences in protooncogene expression in response to $\mathrm{AoC}$ were observed much earlier than proliferation of fibroblast could take place; and $(c)$ there is no evidence for exuberant proliferation of fibroblasts sufficient to dilute the cardiac-specific mRNAs by $\sim 50 \%$ in the old heart preparations, since the total RNA content increased by only $4 \%$ after $\mathrm{AoC}$ in the old rats.

In contrast to previous studies (18-20), expression of the $\mathrm{SR} \mathrm{Ca}^{2+}$-ATPase in our study remained unchanged in response to AoC in the adult rats. This is most likely due to a moderate degree of pressure overload (a mean of 33- $\mathrm{mmHg}$ increase in 
LV systolic pressure) used in our study. Ventricular dry weight/ body weight ratio increased by $>40 \%$ in other studies $(18,19)$, but by only $23 \%$ in ours. It has been demonstrated that the level of the SR $\mathrm{Ca}^{2+}$-ATPase mRNA does not change in mild to moderate LV hypertrophy in young rats (20). However, more severe pressure overload was not feasible in this study, because operative mortality was unacceptably high $(>50 \%)$ in the aged rats.

We examined expression of the cardiac genes only at mRNA level, and it is possible that some translational or posttranslational controls may be present in regulation of these genes. However, previous studies have shown that the mRNA and protein levels of the SR $\mathrm{Ca}^{2+}$-ATPase $(18,20), \operatorname{ANF}(16)$, and MHCs (14) changed in a parallel fashion in the LV myocardium subjected to pressure overload. Although yet to be proven formally, it is likely that the changes in the mRNA levels in our study are likely to be reflected to those of the corresponding proteins.

At present, we do not know whether our findings are unique to this experimental model or are more general phenomena. If we can extrapolate our findings to human subjects, the present study suggests the possibility that the diminished ability to induce proto-oncogenes in response to hemodynamic overload, as well as the age-related differences in cardiac gene expression, may contribute to the higher frequency of heart failure in old patients than in young cohorts subjected to similar hemodynamic stress. Although an acute obstruction of ascending aorta is extremely rare in the clinical setting, other kinds of acute hemodynamic overload, such as acute myocardial infarction and acute mitral regurgitation, are very common in aged patients. Altered expression of a variety of cardiac gene expression might be related to systolic and diastolic dysfunction, which is observed often in old patients.

\section{Acknowledgments}

We thank Dr. Yutaka Kagaya for his excellent surgical assistance, Dr. R. D. Rosenberg for support, Dr. David H. MacLennan for his kind gift of the rabbit cardiac-slow twitch skeletal SR $\mathrm{Ca}^{2+}$-ATPase cDNA, Dr. M. E. Greenberg for c-fos cDNA, Dr. M. Karin for c-jun cDNA, and Elaine $\mathrm{Wu}$ for her technical assistance.

This work was supported in part by a grant from the American Federation for Aging Research and Bayer Fund for Cardiovascular Research to S. Izumo.

\section{References}

1. Zak, R. 1984. Overview of the growth process. In Growth of the Heart in Health and Disease. R. Zak, editor. Raven Press, New York. 1-24.

2. Grossman, W. 1980. Cardiac hypertrophy: useful adaptation or pathologic process? Am. J. Med. 69:576-584.

3. Alpert, N. R., editor. Perspectives in Cardiovascular Research, Myocardial Hypertrophy and Failure. Raven Press, New York. 1983.

4. Katz, A. M. 1990. Cardiomyopathy of overload: a major determinant of prognosis in congestive heart failure. $N$. Engl. J. Med. 322:100-110.

5. Wei, J. Y., and B. J. Gersh. 1987. Heart disease in the elderly. Curr. Probl. Cardiol. 12:1-65.

6. Weisfeldt, M. L., E. G. Lakkata, and G. Gerstenblith. 1988. Aging and cardiac disease. In Heart Disease. A Text Book of Cardiovascular Medicine. 3rd ed. E. Braunwald, editor. W. B. Saunders Co., Philadelphia/London/Toronto. $1650-1662$.

7. McCafferty, W. B., and D. W. Edington. 1974. Skeletal muscle and organ weights of aged and trained male rats. Gerontologia. 20:44-50.

8. Isoyama, S., J. Y. Wei, S. Izumo, P. Fort, F. J. Schoen, and W. Grossman.
1987. Effect of age on the development of cardiac hypertrophy produced by aortic constriction in the rat. Circ. Res. 61:337-345.

9. Isoyama, S., W. Grossman, and J. Y. Wei. 1988. Effects of age on myocardial adaptation to volume overload in the rat. J. Clin. Invest. 81:1850-1857.

10. Izumo, S., B. Nadal-Ginard, and V. Mahdavi. 1988. Proto-oncogene induction and reprogramming of cardiac gene expression produced by pressure overload. Proc. Natl. Acad. Sci. USA. 85:339-343.

11. Schneider, M. D., and T. G. Parker. 1990. Cardiac myocytes as targets for the action of peptide growth factors. Circulation. 81:1443-1456.

12. Morgan, H. E., and K. M. Baker. 1991. Cardiac hypertrophy: mechanical, neural and endocrine dependence. Circulation. 83:13-25.

13. Lompre, A. M., K. Schwartz, A. D'Albis, G. Lacombe, N. V. Thiem, and B. Swynghedauw. 1979. Myosin isoenzyme redistribution in chronic heart overload. Nature (Lond.). 282:105-107.

14. Izumo, S., A. M. Lompre, R. Matsuoka, G. Koren, K. Schwartz, B. NadalGinard, and V. Mahdavi. 1987. Myosin heavy chain messenger RNA and protein isoform transitions during cardiac hypertrophy. Interaction between hemodynamic and thyroid hormone-induced signals. J. Clin. Invest. 79:970-977.

15. Schwartz, K., D. de la Bastie, P. Bouveret, P. Oliviero, S. Alonso, and M. Buckingham. 1986. $\alpha$-Skeletal muscle actin mRNAs accumulate in hypertrophied adult rat hearts. Circ. Res. 59:551-555.

16. Day, M. L., D. Schwartz, R. C. Wiegand, P. T. Stockman, S. R. Brunnert, H. E. Trulunay, M. G. Currie, D. G. Standaert, and P. Needleman. 1987. Ventricular atriopeptin. Unmasking of messenger RNA and peptide synthesis by hypertrophy or dexamethasone. Hypertension. 9:485-491.

17. Mercadier, J.-J., J.-L. Samuel, J.-B. Michel, M.-A. Zongazo, D. de la Bastie, A.-M. Lompre, C. Wisnewsky, L. Rappaport, B. Levy, and K. Schwartz. 1989. Atrial natriuretic factor gene expression in rat ventricle during experimental hypertension. Am. J. Physiol. 257:H979-H987.

18. Komuro, I., M. Kurabayashi, Y. Shibazaki, F. Takaku, and Y. Yazaki. 1989. Molecular cloning and characterization of $\mathrm{a} \mathrm{Ca}^{2+}+\mathrm{Mg}^{2+}$-dependent adenosine triphosphatase from rat cardiac sarcoplasmic reticulum. Regulation of its expression by pressure overload and developmental stage. J. Clin. Invest. 83:1102-1108.

19. Nagai, R., A. Zarain-Herzberg, C. J. Brandl, J. Fujii, M. Tada, D. H. MacLennan, N. R. Alpert, and M. Periasamy. 1989. Regulation of myocardial $\mathrm{Ca}^{2+}$-ATPase and phospholamban mRNA expression in response to pressure overload and thyroid hormone. Proc. Natl. Acad. Sci. USA. 86:2966-2970.

20. De la Bastie, D., D. Levitsky, L. Rappaport, J.-J. Mercadier, F. Marotte, C. Wisnewsky, V. Brovkovich, K. Schwartz, and A.-M. Lompre. 1990. Function of the sarcoplasmic reticulum and expression of its $\mathrm{Ca}^{2+}$-ATPase gene in pressure overload-induced cardiac hypertrophy in the rat. Circ. Res. 66:554-564.

21. Lakatta, E. G., and F. C. P. Yin. 1982. Myocardial aging: functional alterations and related cellular mechanisms. Am. J. Physiol. 242:H927-H941.

22. Anversa, P., B. Hiler, R. Ricci, G. Guideli, and G. Olivetti. 1986. Myocyte cell loss and myocyte hypertrophy in the aging rat heart. J. Am. Coll. Cardiol. 8:1441-1448.

23. Anversa, P., E. Puntillo, P. Nikitin, G. Olivetti, J. M. Capasso, and E. H. Sonnenblick. 1989. Effects of age on mechanical and structural properties of myocardium of Fisher 344 rats. Am. J. Physiol. 256:H1440-H1449.

24. Capasso, J. M., A. Malhotra, R. M. Remily, J. Scheuer, and E. H. Sonnenblick. 1983. Effects of age on mechanical and electrical performance of rat myocardium. Am. J. Physiol. 245:H72-H81.

25. Effron, M. B., G. M. Bhatnagan, H. A. Spurgeon, G. Ruano-Arroyo, and E. G. Lakatta. 1987. Changes in myosin isozymes, ATPase activity, and contraction duration in rat cardiac muscle with aging can be modulated by thyroxine. Circ. Res. 60:238-248.

26. Farrar, R. P., J. W. Stranes, G. D. Cartee, P. Y. Oh, and H. L. Sweeney. 1988. Effects of exercise on cardiac myosin isozyme composition during the aging process. J. Appl. Physiol. 64:880-883.

27. Froelich, J. P., E. G. Lakatta, E. Bread, H. A. Spurgeon, M. L. Weisfeldt, and G. Gerstenblith. 1978. Studies of sarcoplasmic reticulum function and contraction in young adult and aged rat myocardium. J. Mol. Cell. Cardiol. 10:427438.

28. Narayanan, N. 1987. Comparison of ATP-dependent calcium transport and calcium-activated ATPase activity of cardiac sarcoplasmic reticulum from rats of various ages. Mech. Ageing Dev. 38:127-143.

29. Angel, P., E. A. Allegretto, S. T. Okino, K. Hattori, W. J. Boyle, T. Hunter, and M. Karin. 1988. Oncogene jun encodes a sequence-specific trans-activator similar to AP-1. Nature (Lond.). 332:166-171.

30. MacLennan, D. H., C. J. Brandl, B. Korczak, and N. M. Green. 1985 Amino-acid sequence of a $\mathrm{Ca}^{2+}-\mathrm{Mg}^{2+}$-dependent ATPase from rabbit muscle sarcoplasmic reticulum, deduced from its complementary DNA sequence. $\mathrm{Na}$ ture (Lond.). 316:696-700.

31. Scott, B. T., H. K. B. Simmerman, J. H. Collins, B. Nadal-Ginard, and L. B. Jones. 1988. Complete amino acid sequence of canine cardiac calsequestrin deduced by cDNA cloning. J. Biol. Chem. 263:8958-8964.

32. Seidman, C. E., A. D. Duby, E. Choi, R. M. Graham, E. Haber, C. J. 
Homcy, J. A. Smith, and J. G. Seidman. The structure of rat preproatrial natriuretic factor as defined by a DNA clone. Science (Wash. DC). 225:325-326.

33. Taubman, M. B., C. W. J. Smith, S. Izumo, J. W. Grant, T. Endo, A Andreadis, and B. Nadal-Ginard. 1989. The expression of sarcomeric musclespecific contractile protein genes in $\mathrm{BC} 3 \mathrm{H} 1$ cells: $\mathrm{BC} 3 \mathrm{H} 1$ cells resemble skeleta myoblasts that are defective for commitment to terminal differentiation. J. Cell. Biol. 108:1799-1806.

34. Fort, P., L. Marty, M. Piechaczyk, S. E. Sabrouty, C. Dani, P. Jaenteur, and J. M. Blanchard. 1985. Various rat adult tissues express only one major mRNA species from the glyceraldehyde-3-phosphate-dehydrogenase multigenic family. Nucleic Acids Res. 13:1431-1442.

35. Mendez, R. E., J. M. Pfeffer, F. V. Ortola, K. D. Bloch, S. Anderson, J. G. Seidman, and B. M. Brenner. 1987. Atrial natriuretic peptide transcription, storage and release in rats with myocardial infarction. Am. J. Physiol. 253:H1449H1455.

36. Berger, S. L., and A. R. Kimmel, editors. 1987. Methods in Enzymology,
Volume 152. Guide to Molecular Cloning Techniques. Academic Press, Orlando, Fl. pp. 812.

37. Wallenstein, S., C. L. Zucker, and J. L. Fleiss. 1980. Some statistical methods in circulation research. Circ. Res. 27:1-9.

38. Maciel, L. M. Z., R. Polikar, D. Rohrer, B. K. Popovich, and W. H Dillman. 1990. Aged-induced decreases in the messenger RNA coding for the sarcoplasmic reticulum $\mathrm{Ca}^{2+}$-ATPase of the rat heart. Circ. Res. 67:230-234.

39. Seshadri, T., and J. Campisi. 1990. Repression of c-fos transcription and an altered genetic program in senescent human fibroblasts. Science (Wash. DC) 247:205-209.

40. Paulsson, Y., M. Bywater, S. Pfeifer-Ohlsson, R. Ohlsson, S. Nilsson, C.-H. Heldin, B. Westermark, and C. Betsholz. 1986. Growth factors induce early pre-replicative changes in senescent human fibroblasts. EMBO (Eur. Mol. Biol. Organ.) J. 5:2157-2162.

41. Schunkert, H., L. Jahn, S. Izumo, C. S. Apstein, and B. H. Lorell. 1991 Localization and regulation of c-fos and c-jun protooncogene induction by systolic wall stress in normal and hypertrophied rat hearts. Proc. Natl. Acad. Sci. USA. 88:11480-11484. 